\title{
Electrochemical Synthesis and Morphology Investigation with Respect to Parameters on Metal, Metaloxide Composite
}

Vanitha. $C^{l, *}$, and Kannusamy. $R^{l}$

${ }^{1}$ Department of Electronics, PSG College of Arts \& Science, Coimbatore-641014

Email: cvanitha95@gmail.com

\begin{abstract}
Fine tuning proper parametric condition is the key factor to attain the required morphology on synthesis process. Perfect synthesis task can pave strong foundation towards application part such as vertical oriented, uniformed hybrid one dimension nanostructures can lead fabrication of nano electronic devices. Nanostructures in the form of zero, one and two dimensions will selectively fulfil the design aspect of transition metal oxide based electrodes for energy devices and sensors. This research paper have been examined the impact of various synthesis parameters listed as template assisted deposition, change in electrode position, deposition potential and direct deposition on copper substrate with zinc nitrate hexahydrate salt in liquid form for constant precursor concentration. Synthesis done through electrochemical deposition method using two electrode electrochemical cell with copper substrate acts as working electrode, platinum as counter electrode, Polycarbonate membrane with $200 \mathrm{~nm}$ pores as template, for characterization Scanning Electron Microscopy, Field Emission Scanning Electron Microscopy techniques were used to obtain morphology analysis of the samples. Result revealed the morphology based on variation in synthesis parameter also shown limitation on template with random pores and narrow exposure of counter electrode. Scrutiny process of precursor concentration with respective characterization analysis of prior work was considered as reference for this work.
\end{abstract}

Keywords: Synthesis, Template, Electrode potential, Electrode position, Morphology

\section{Introduction}

Zinc oxide is an intrinsically $\mathrm{n}$ type semiconducting material with wide band gap $3.37 \mathrm{eV}$ and large binding energy $60 \mathrm{meV}$ at room temperature, which is abundant in nature so economical and versatile for different kind of electronic applications. These facts are the potential reasons which attract many researchers towards the choice of $\mathrm{ZnO}$ material for their work [1]. To do synthesis of selective material there are two major classifications based on methodology, one is the wet process and another one is the dry process. Sol-Gel, Hydrothermal, Chemical Bath Deposition and Electrochemical Deposition methods are examples for wet chemical process. Chemical Vapour Deposition, Physical Vapour Deposition, Pulse Laser Deposition, Metal Organic Chemical Vapour Deposition and Molecular Beam Epitaxial methods are examples for dry chemical process. When compared with wet process, dry process requires very high temperature, high 
pressure environment with limited choice of substrates made the experimental setup expensive. So feasibility of usage got affected to obtain the required structure and morphology. Methods under wet chemical process can fulfil the expectation of researchers regarding synthesis to obtain uniformed, highly purified crystalline as well as polycrystalline materials with low cost of experimental setup at atmospheric pressure and low temperature environment $[1,2]$. Among wet chemical methods, electrochemical deposition is the widely used and economical approach for the fabrication of metal oxide materials. Peulon et.al and Izaki et.al had performed the pioneering work in the field of electrodeposition to obtain $\mathrm{ZnO}$ thin film and nanorods [3-10]. Electrochemical synthesis can lead path for control on synthesis parameters of highly active materials with an efficient way [11].

In nanomaterials three different morphologies can be categorized as $0 \mathrm{D}, 1 \mathrm{D}$ and $2 \mathrm{D}$ structures. To attain required morphology of the material is the significant factor, which decides the performance measure of various electronic device applications. Template based synthesis has become the most common technique for the fabrication of $1 \mathrm{D}$ nanostructures. When compared with template free synthesis, template based synthesis provide an easy way to achieve confinement on growth of 1D nanostructures [12-15]. Templates can either be prepared in the laboratory or readymade templates are available in the market with different pore aspect ratios. Depends upon the choice of synthesis and parametric conditions, suitable template should be chosen for the task. Anodic Alumina Oxide (AAO), Diblock Copolymers (PMMA), DNA Molecule, Mesoporous Molecular Sieves (MCM-41), Nano Channel Glass (NCG), and Poly Carbonate Membranes (PCM) are some of the readily available template examples. Among them AAO and PCM are the most commonly used templates by researchers. The template assisted method is successful to control the morphology of nano and microstructures [16-18]. Precursor concentration and deposition duration are the important factors among other parameters because which essentially decides the resultant morphology dimension of material on synthesis process.

In this work we have synthesized $\mathrm{ZnO}$ nanostructures using electrochemical deposition method, made changes on its parameters for constant precursor concentration to understand the reflection of individual parameter variation in terms of morphology analysis. Morphology plays major role in applications regarding their performance measure, for example fabrication of electrodes in super capacitors and fabrication of various other electronic devices. Determination of constant precursor concentration with respective structure information and elemental composition were obtained from prior work results and considered as reference. In this work Scanning Electron Microscope (SEM) and Field Emission Scanning Electron Microscope (FESEM) characterization techniques were used to confirm morphology changes against variation on individual synthesis parameter.

\section{Experimental}

a. Materials and Instruments

Chemicals zinc nitrate hexahydrate, hexa methylene tetra amine, dichloromethane were purchased from spectrum make. Commercially available platinum electrode was used as counter electrode and self adhesive copper tape with area $1 \mathrm{~cm}^{2}$ was used as working electrode. Whatman product of polycarbonate track etched membrane (PCTE/PCM) circles $(25 \mathrm{~mm}$ diameter) with randomly oriented $200 \mathrm{~nm}$ pores were used as 
template. REMI 1MLH hot plated magnetic stirrer was used for synthesis task. Scanning electron microscope (EVO 18, Carl Zeiss), Zeiss SIGMA field-emission scanning electron microscope instruments were used for morphology analysis.

\section{b. Method}

$\mathrm{ZnO}$ nanostructures, synthesized by using template assisted and direct deposition method through electrochemical deposition technique. Templates cleaned by magnetic stirring process in de-ionised water for twenty minutes duration at room temperature. Copper tape was used as substrate for the growth and the template was placed on it. In two electrode electrochemical cell (arrangement made with 100ml glass beaker) copper tape acts as a working electrode and the commercial platinum electrode acts as counter electrode. Electrolyte containing 100ml DI water, 1:1 ratio of 0.002 molar zinc nitrate hexahydrate salt in liquid form and hexa methylene tetra amine (HMTA) mixture which was magnetically stirred at room temperature with $900 \mathrm{rpm}$ for thirty minutes duration. While heating, let the template immersed in the electrolyte for seven minutes long to wet the pore walls to enhance material deposition inside the pores. When the electrolyte temperature reaches $75^{\circ} \mathrm{C}$ the pellet removed from beaker and placed the working electrode (copper tape) at the bottom surface of the beaker made the template pores facing upward direction then placed the counter electrode (platinum) straight above which was facing down toward the working electrode for deposition. Above discussed information's were common for following synthesis process except few changes made among parameters between every other mentioned under each category.

Template free deposition - Process was carried out in the range of $75^{\circ} \mathrm{C}-85^{\circ} \mathrm{C}$ bath temperature. The electrochemical deposition was achieved at $-1.2 \mathrm{~V}$ potential with the growth duration maintained up to 15 minutes. Deposition would occur directly on one side of the copper substrate and another side was insulated by brown tape to avoid unwanted deposition of the material. Further the copper substrate was placed on a slice of glass to enhance surface rigidity while deposition and followed this practice.

Template assisted deposition - Here material growth occurred through randomly oriented template pores of PCM placed upon copper substrate. Following set of parameter variations on synthesis was tested.

(i) Synthesis process maintained the same range of bath temperature $\left(75^{\circ} \mathrm{C}-85^{\circ} \mathrm{C}\right)$, electrode potential ($1.2 \mathrm{~V}$ ) and growth duration (15 minutes) as in template free deposition.

(ii) Synthesis process maintained the reverse range of bath temperature $\left(80^{\circ} \mathrm{C}-75^{\circ} \mathrm{C}\right)$ by switch off the heater when reached $80^{\circ} \mathrm{C}$ and allowed the deposition till the bath temperature reduced up to $75^{\circ} \mathrm{C}$ with electrode potential(-1.2V), the deposition process carried out for 14 minutes duration.

(iii) Synthesis process with increase of electrode potential and bath temperature, here the entire deposition was carried out at $\sim 85^{\circ} \mathrm{C}$ constant bath temperature. Deposition potential maintained with the increase of $50 \%$ from the rest as $-1.8 \mathrm{~V}$ for 15 minutes growth duration.

After the deposition process the sample was left for air dried overnight. To dissolve the template it should be immersed in water free dichloromethane for two minutes approximately. After each and every chemical 
treatment the sample should be rinsed thoroughly in de-ionized water to avoid residual impurities. Then the samples were examined by using SEM, FESEM techniques to obtain the morphology details of the growth.

c. Results and Discussion

In the earlier template assisted synthesis task, we found that variation in morphology based on modified molar concentration of precursors. Following table 1, figures 1, $2 \& 3$ shown the reference information. Table 1 represents the measure of synthesis parameters were maintained at earlier phase (i) experimental work on template assisted electro deposition process [12]. While the period of phase (i) experiment, condition of zinc nitrate hexahydrate salt was in solid state and the position of the electrodes were kept in adjacent and opposite. Fig.1. shown the XRD pattern with peaks $2 \theta=31.71,34.40 \& 36.06$ degrees matched to hkl elements (100), (002) \& (101) which agrees with the reflection of hexagonal wurtzite structured polycrystalline ZnO (JCPDS 01-076-0704).

Table 1. Parametric specification of synthesis phase (i).

\begin{tabular}{|c|c|c|c|c|c|c|c|}
\hline \multirow{2}{*}{$\begin{array}{l}\text { S. } \\
\text { No }\end{array}$} & \multirow{2}{*}{$\begin{array}{l}\mathrm{Zn}\left(\mathrm{NO}_{3}\right)_{2} . \\
6 \mathrm{H}_{2} \mathrm{O}\end{array}$} & \multirow[t]{2}{*}{$\left(\mathrm{CH}_{2}\right)_{6} \mathrm{~N}_{4}$} & \multirow{2}{*}{$\begin{array}{l}\text { DI } \\
\text { Water } \\
(\mathrm{ml})\end{array}$} & \multirow[t]{2}{*}{$\mathrm{pH}$} & \multicolumn{3}{|l|}{ Deposition } \\
\hline & & & & & $\begin{array}{l}\text { Temperature } \\
\left({ }^{\circ} \mathrm{C}\right)\end{array}$ & $\begin{array}{l}\text { Potential } \\
\text { (V) }\end{array}$ & $\begin{array}{l}\text { Time } \\
\text { (Minutes) }\end{array}$ \\
\hline I & $0.04 \mathrm{M}$ & $0.04 \mathrm{M}$ & 200 & 5.5 & $75-80$ & -1.2 & 20 \\
\hline II & $0.02 \mathrm{M}$ & $0.02 \mathrm{M}$ & 200 & 6 & $75-80$ & -1.2 & 20 \\
\hline III & $0.002 \mathrm{M}$ & $0.002 \mathrm{M}$ & 100 & 6 & $\sim 80$ & -1.2 & 10 \\
\hline
\end{tabular}

Fig.2. had shown the morphology details of 1D nanorods were produced through the pores by reducing one order the precursor concentration from previous $0.02 \mathrm{M}$ and kept $0.002 \mathrm{M}$. Initially to obtain $1 \mathrm{D}$ nanostructure, major modification made only on molar concentration of precursor rest of the synthesis parameters were similar for first two samples, third sample synthesized with slightly less process duration and approximately constant bath temperature $\left(\sim 80^{\circ} \mathrm{C}\right)$, reduction of electrochemical cell circumference along with the solvent. Precursor concentration of 1D (0.002M) with $100 \mathrm{ml}$ beaker as electrochemical cell were considered as constant for further experiments regarding morphology analysis. EDX analysis (Fig.3.) of the sample confirmed the following that growth consists only zinc and oxygen elements, also presence of cu peaks in the spectrum due to the impact of substrate and ensure that no other impurities. 


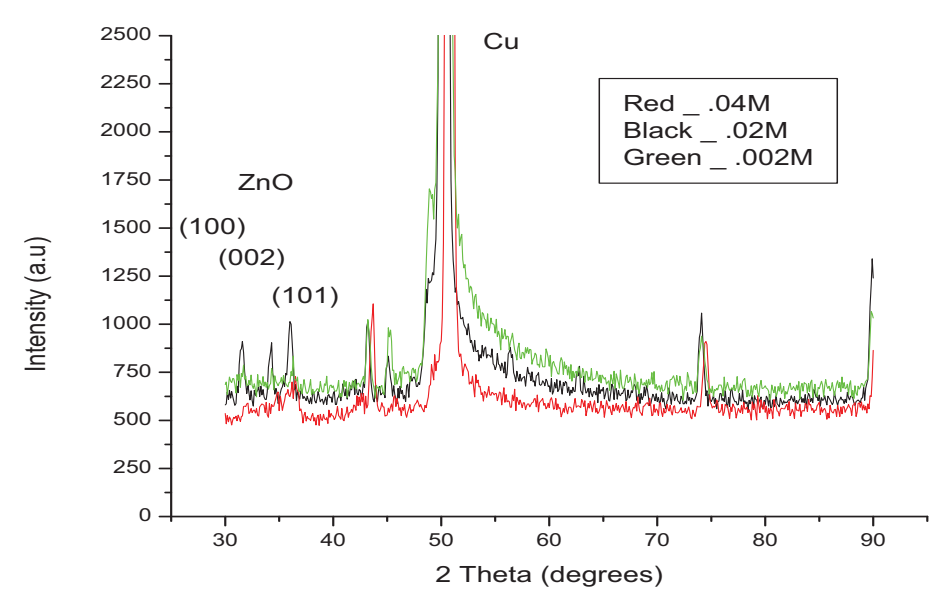

FIG 1. XRD Pattern of $\mathrm{ZnO}$ for $0.04 \mathrm{M}$ (Red), $0.02 \mathrm{M}$ (Black) and $0.002 \mathrm{M}$ (Green) precursor concentration.

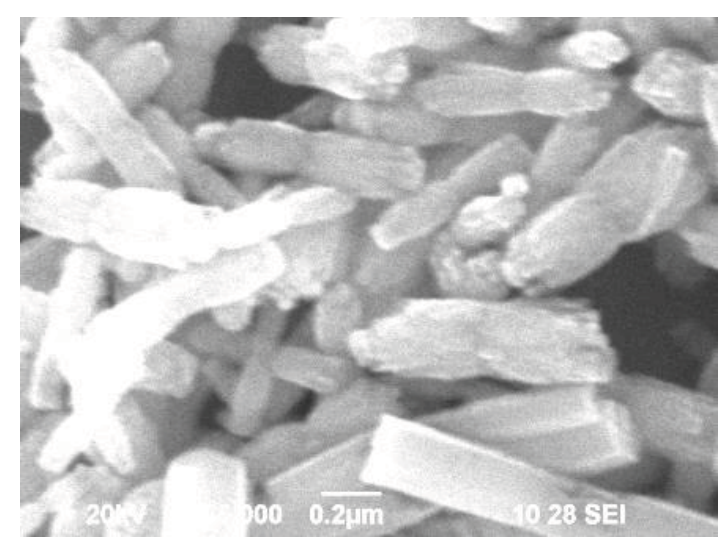

FIG 2. SEM image of Nanorods for 0.002M precursor concentration.

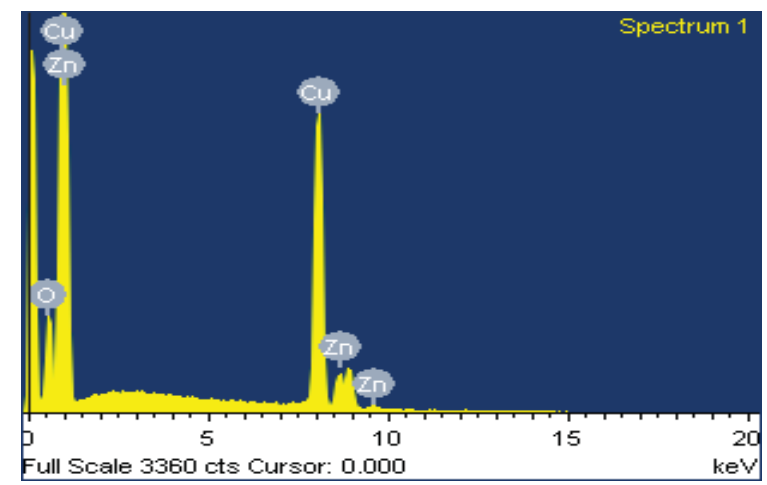

\begin{tabular}{|c|c|c|}
\hline Element & $\begin{array}{c}\text { Atomic } \\
\%\end{array}$ & $\begin{array}{c}\text { Weight } \\
\%\end{array}$ \\
\hline $\mathrm{O}$ & 12.87 & 37.04 \\
\hline $\mathrm{Zn}$ & 8.32 & 5.86 \\
\hline
\end{tabular}

FIG 3. EDX Spectrum with respective table for $0.002 \mathrm{M}$ concentration. 
Table 2 represents the measure of synthesis parameters which were maintained for phase (ii) experiment work. Fig 4 (a) \& (b) shown FESEM images of lower and higher magnitude for template free deposition which revealed the morphology looks like bunch of rose flowers. While deposition the ammeter current varied from $-016 \mu \mathrm{A}$ at the beginning and reached $-006 \mu \mathrm{A}$ constant at the end of the process period.

Table 2. Parametric specification of synthesis phase (ii).

\begin{tabular}{|c|c|c|c|c|c|c|c|}
\hline \multirow{2}{*}{$\begin{array}{l}\text { S. } \\
\text { No }\end{array}$} & \multirow{2}{*}{$\begin{array}{l}\mathrm{Zn}\left(\mathrm{NO}_{3}\right)_{2} \\
.6 \mathrm{H}_{2} \mathrm{O}\end{array}$} & \multirow[t]{2}{*}{$\left(\mathrm{CH}_{2}\right)_{6} \mathrm{~N}_{4}$} & \multirow{2}{*}{$\begin{array}{l}\text { DI } \\
\text { Water } \\
(\mathrm{ml})\end{array}$} & \multirow[t]{2}{*}{$\mathrm{pH}$} & \multicolumn{3}{|l|}{ Deposition } \\
\hline & & & & & $\begin{array}{l}\text { Temperature } \\
\left({ }^{0} \mathrm{C}\right)\end{array}$ & $\begin{array}{l}\text { Potential } \\
\text { (V) }\end{array}$ & $\begin{array}{l}\text { Time } \\
\text { (Minutes) }\end{array}$ \\
\hline I & $.002 \mathrm{M}$ & $.002 \mathrm{M}$ & 100 & 6 & $75-85$ & -1.2 & 15 \\
\hline II & $.002 \mathrm{M}$ & $.002 \mathrm{M}$ & 100 & 6 & $75-85$ & -1.2 & 15 \\
\hline III & $.002 \mathrm{M}$ & $.002 \mathrm{M}$ & 100 & 6 & $80-75$ & -1.2 & 14 \\
\hline IV & $.002 \mathrm{M}$ & $.002 \mathrm{M}$ & 100 & 6 & $\sim 85$ & -1.8 & 15 \\
\hline
\end{tabular}

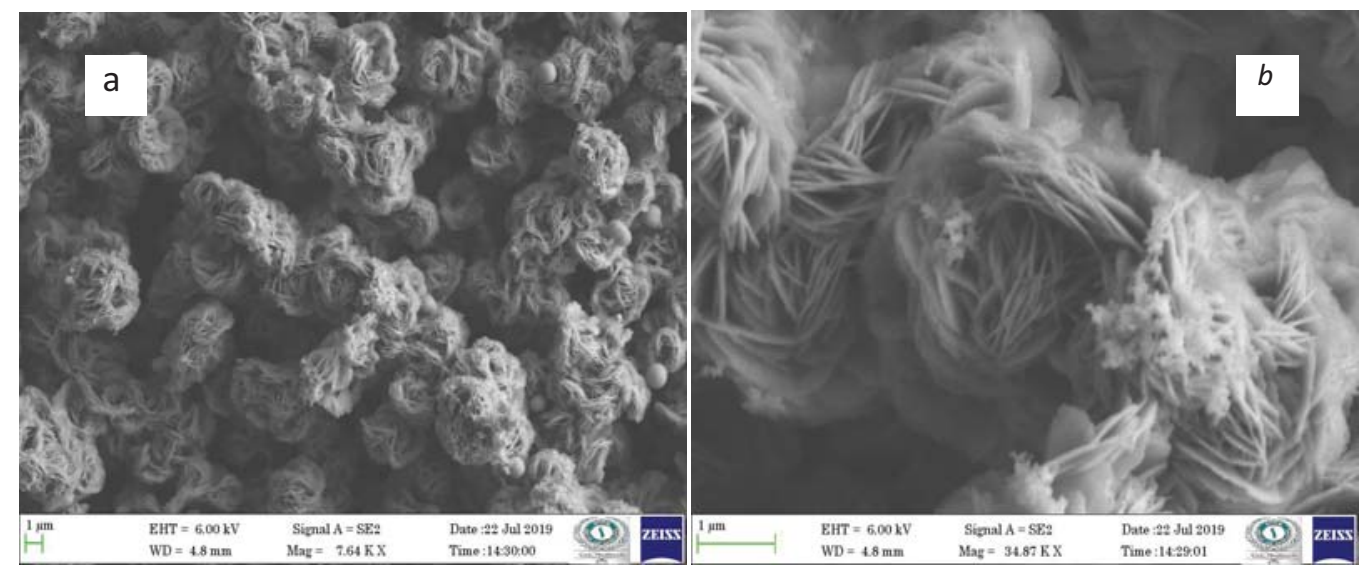

FIG 4. FESEM image of template free deposition with bunch of nanoroses like morpholgy (a) on lower magitude (b) on higher magitude. 


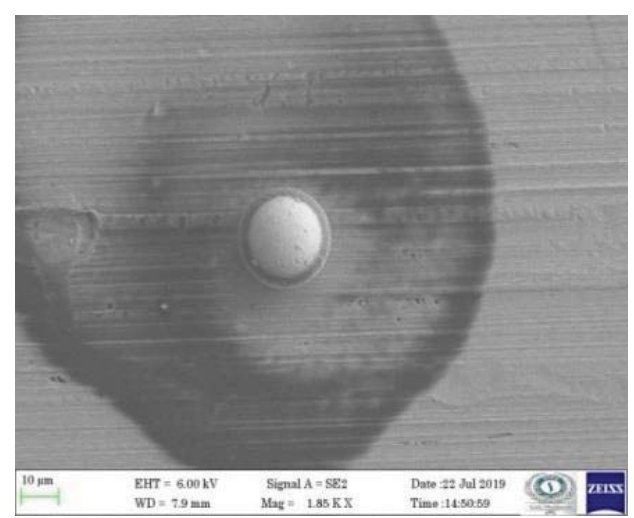

FIG 5. FESEM image of template assisted deposition with tennis ball like morphology for $\left(75^{\circ} \mathrm{C}-85^{\circ} \mathrm{C}\right)$ bath temperature.

Figure 5 shown FESEM images of template assisted electro deposition, where template pore filled with material which resembles a tennis ball like image for $\left(75^{\circ} \mathrm{C}-85^{\circ} \mathrm{C}\right)$ bath temperature at $-1.2 \mathrm{~V}$ electrode potential. Deposition current varied from $-016 \mu \mathrm{A}$ at the beginning and reached $-006 \mu \mathrm{A}$ constant at the end of process period. Figure $6 \& 7$ shown SEM image of template assisted deposition with reverse range of bath temperature $\left(80^{\circ} \mathrm{C}-75^{\circ} \mathrm{C}\right)$ produced hollow tube like $1 \mathrm{D}$ morphology along with diameter measurements. In figure 6 bottom right corner had shown the clear view of vertical orientated tube like structure. 1D growth with uneven aspect ratio can be avoided by following careful synthesis procedure for example while heating the electrolyte wet pore walls to enhance the deposition, template had been immersed in electrolyte for seven minutes long this might reacted on template material pore aspect ratio. Need attention regarding template pore walls wet task and choice of effective counter electrode area. During the electrochemical deposition process the ammeter current variation starts from $-077 \mu \mathrm{A}$ and retain $001 \mu \mathrm{A}$ constant in the last two minutes of total 14 minutes duration (the moment when bath temperature reduced as $75^{\circ} \mathrm{C}$ ).

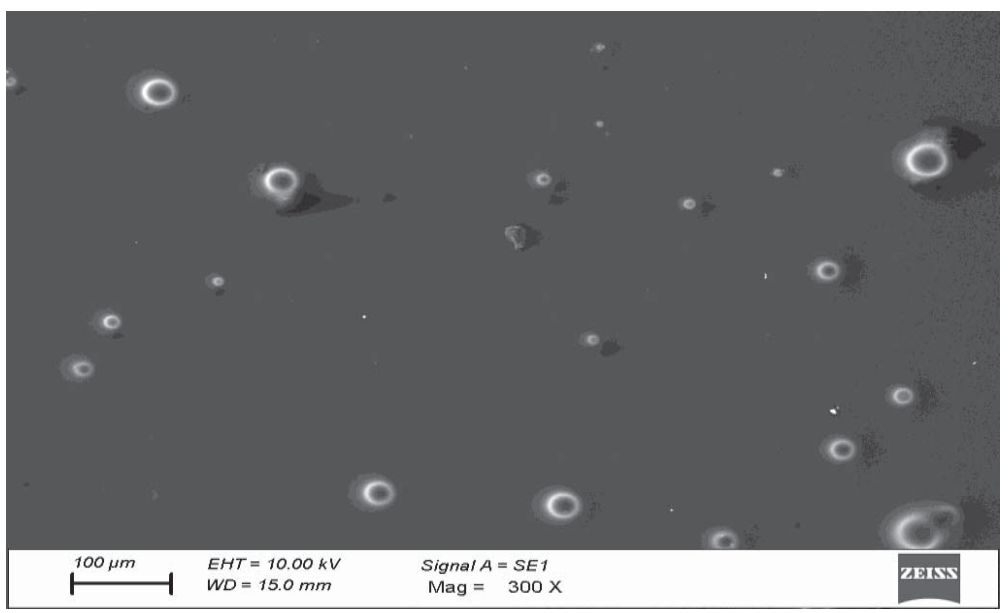

FIG 6. SEM image of template assisted deposition for reverse range of bath temperature $\left(80^{\circ} \mathrm{C}-75^{\circ} \mathrm{C}\right)$ with tube like morpholgy.

33 INTERNATIONAL JOURNAL OF INNOVATIVE RESEARCH IN PHYSICS 


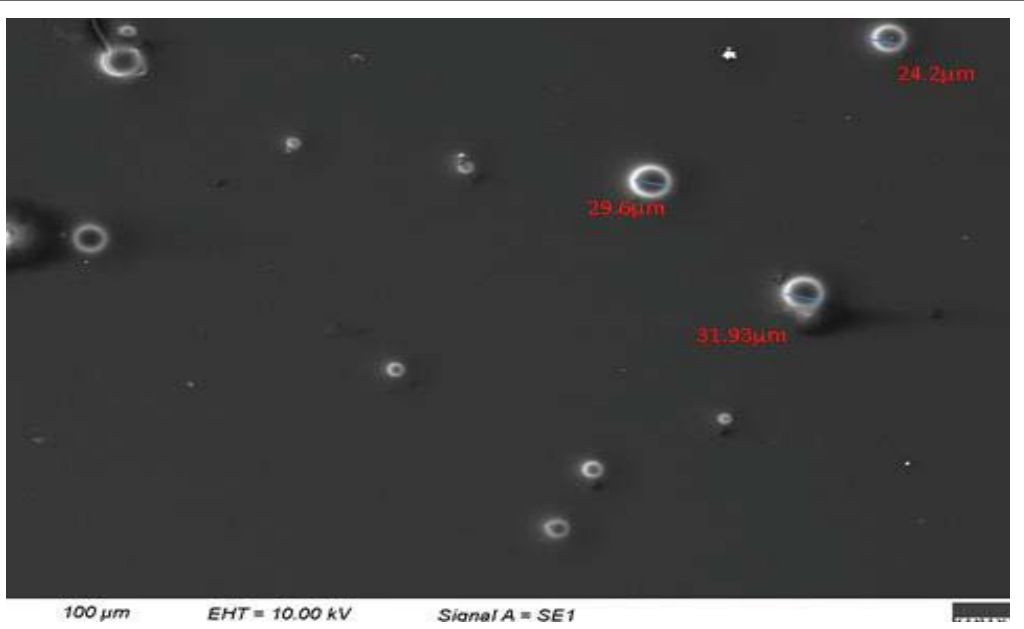

FIG 7. SEM image of template assisted deposition for reverse range of bath temperature $\left(80^{\circ} \mathrm{C}-75^{\circ} \mathrm{C}\right)$ tube like morpholgy with diameter measuements.
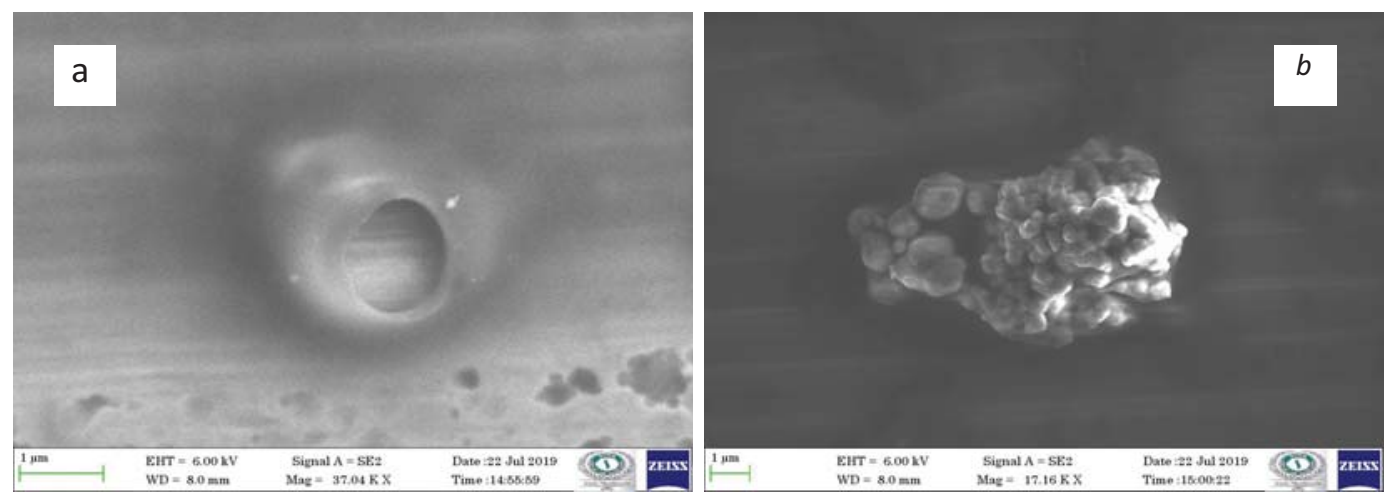

FIG 8. FESEM images of template assisted deposition with high electrode potential (-1.8 V) and bath temperature $\sim 85^{\circ} \mathrm{C}$ (a) Unfilled pore (b) Over deposition around the pore surface.

Figure 8 (a) \& (b) shown unfilled template pore, over deposition of material surrounded the surface of hollow pore. Here the entire deposition process was carried out at $\sim 85^{\circ} \mathrm{C}$ constant bath temperature along with increased deposition potential. Variations in deposition current with respect to time were observed as $123 \mu \mathrm{A}$ at the moment of starting the deposition process, eight minutes after it reached $-55 \mu \mathrm{A}$ and at the end of fifteenth minute maintained $-46 \mu \mathrm{A}$ as constant. 


\section{Conclusion}

This paper had shown the resultant morphology variation for constant precursor concentration $(0.002 \mathrm{M})$ and change on other parameters of electrochemical synthesis. Electro deposition can be obtained at atmosphere pressure, low temperature environment with economically simple experimental setup. In terms of template free deposition 3D like morphology of rose flowers were produced. Template assisted deposition at reverse range of bath temperature shown vertically oriented tubes like morphology where perfect position between electrodes assured the vertical orientation. Hike of electrode potential at high constant temperature resulted over deposition around the pore and unfilled image of pore. When compared with prior experimental result of 1D nanorods (with solid state of Zinc salt), confirmed dilution of material can produce remarkable change on morphology as 1D tube like structures (with liquid state of Zinc salt) for reverse range of bath temperature. As on observation resultant unfilled pores and tube like structures with different diameter were considered as limitation on counter electrode effect with respect to working electrode area and need careful practice in synthesis procedure. According to our understanding from this experimental study suggested that surface area of counter electrode should be considerably significant to achieve complete deposition with uniform morphology. As well as optimisation of electrode potential, proper electrode position, choice of template with ordered, dense pores can provide proper support to attain good morphology conditions on 1D nanostructure.

\section{Acknowledgements}

Sincere gratitude to Indian Academy of Sciences, Bangalore for the learning opportunity they had given through "Refresher Course in Material preparation and measurement of properties" and Indian Institute of Science, Nanotechnology Centre, Bangalore for provided the technical platform through familiarization workshop and hands on training workshop on behalf of Indian Nano Users programme funded by Department of Electronics and Information Technology, Government of India.

\section{REFERENCES}

[1] Sheng $\mathrm{Xu}$, Zhong Lin Wang, One-dimensional $\mathrm{ZnO}$ nanostructures solution growth and functional properties, Press and Springer-Verlag: Berlin Heidelberg (2011)

[2] Thi Ha Tran, Viet Tuyen Nguyen, Hindawi Publishing Corporation 2014, 856592 (2014)

[3] Snehal. L. Kadam, Pallavi. M. Padwal, Shrinivas. B. Kulkarni, Advanced Materials Proceedings 2, 205 (2016)

[4] Mustafa Aghazadeh, J. Anal. Bioanal. Electrochem. 8, 961 (2018)

[5] Shuxi Dai, Yinyong Li, Zuliang Du, Kenneth. R. Carter, J. Electrochem. Soc. 160, 156 (2013)

[6] X. Z. Lan, Y. Jiang, X. M. Liu, W. J. Wang, D. Wu, C. Liu, Y. G. Z1hang, H. H. Zhong, J. Crystal Growth \& Design 11, 3837 (2011)

[7] S. Peulon, D. Lincot, J. Adv. Mater. 8, 166 (1996) 
[8] M. Izaki, T. Omi, J. Appl. Phys. Lett. 68, 2439 (1996)

[9] M. Izaki, T. Omi, J. Electrochem. Soc. 144, 1949 (1997)

[10] Fazel Ghahramanifard, Ahmad Rouhollahi*,Omid Fazlolahzadeh, J. Anal. Bioanal. Electrochem. 10, 362 (2018)

[11] Lawrence, Matthew.J, Kolodziej, Adam, Rodriguez, Paramaconi, Curr. Opin. Electrochem. 10, 7 (2018)

[12] Mohamed Shaban, Amin Hussein, Ahmed Abdel Khalek, Hany. S, Hamdy, J. Appl. Chem. 7, 4 (2014)

[13] C.Vanitha, R.Murugesan, N.Pasupathy, IEEE sponsored International Conference on Electronics and Communication Systems Proceeding IV, 1729 (2016)

[14] Li Shaolan, Zhang Lichun, J. Semicond. 34, 11 (2013)

[15] Jing Zhangi, Yingxue Cuil, Guangcun Shan, arXiv: 1905.01766 (2019)

[16] S. Devan, J. Adv. Funct. Mat. (2012)

[17] Sylvie Beaufils, Thierry Rouillon, Pierre Millet, Jean Le Bideau, Pierre Weiss, Jean - Paul Chopart, Anne - Lise Dalin, J. Mat. Sci. Eng. 9, 333 (2019)

[18] Canlin Ou, Pedro Enrique Sanchez-Jimenez, Anuja Datta, Francesca. L, Boughey, Richard. A. Whiter, SumanLata Sahonta, Sohini Kar-Narayan, J. ACS Appl. Mater. Interfaces 22, 13678 (2016) 